\title{
ADHERBAL TOLOSA
}

\author{
DADOS BIOGRAFICOS
}

Adherbal Pinheiro Machado Tolosa nasceu em São Manoel do Paraíso, a 22 de dezembro de 1899. Educou-se na cidade de São Paulo, onde completou o curso primário e fêz estudos secundários, diplomando-se no Ginásio do Estado. Em 1918 matriculou-se na Faculdade de Medicina e Cirurgia de São Paulo, diplomando-se em 1923.

Desde a mocidade Adherbal Tolosa demonstrou amor ao estudo. No Ginásio do Estado, ao conquistar o bacharelado em ciêrıcias e letras, recebeu o prêmio "Antônio de Godoi", destinado ao aluno que mais se distinguisse na turma. Durante o curso médico, a tenacidade no estudo, a dedicação aos doentes e a meticulosidade no trabalho o tornaram um dos líderes de sua turma. Sua tese de doutoramento foi aprovada com grande distinção.

Ainda acadêmico, em 1921, foi nomeado interno dos Postos da Liga de Combate à Sífilis, mantidos pelo Centro Acadêmico Oswaldo Cruz, função que desempenhou até o fim do curso médico. Em 1922 e 1923 foi interno

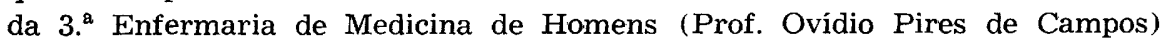
da Santa Casa de Misericórdia de São Paulo. Logo depois de formado, sem abandonar as atividades diárias neste hospital, passou a trabalhar no dispensário "Clemente Ferreira", da Liga Paulista contra a Tuberculose, onde atuou até 1938, adquirindo grande experiência no diagnóstico e tratamento das afecções do aparelho respiratório. De 1925 a 1938 trabalhou também como clínico consultante na Clínica Obstétrica (Prof. Raul Briquet).

Com a criação, em 1924, de nova cadeira de Clínica Médica, confiada ao Prof. A. de Almeida Prado, foi convidado para o cargo de assistente extranumerário da Faculdade de Medicina e Cirurgia de São Paulo, passando a trabalhar na 1. ${ }^{a}$ Enfermaria de Medicina de Homens da Santa Casa. Pouco depois, tendo o Prof. Enjolras Vampré assumido a regência da cadeira de Clínica Psiquiátrica e Moléstias Nervosas, foi convidado para exercer o cargo de $1 .^{\circ}$ assistente e as funções de chefe de clínica, sendo nomeado, interinamente, em maio de 1925 e, em caráter efetivo, em março de 1928. Em março de 1926, por fôrça de decreto então vigente, recebeu o título de Docente-livre de Clínica Neuriátrica e Psiquiátrica. Em 15 de janeiro de 1937 foi reconduzido à Docência-livre de Clínica Neurológica cadeira já desdobrada - mediante concurso de títulos. Em 1938 abandonou tôdas as atividades que vinha exercendo em outros setôres da Medicina e que lhe tinham proporcionado sólida base clínica geral, para dedicar-se exclusivamente à Neurologia. Nesse mesmo ano, em virtude do prematuro falecimento do Prof. Enjolras Vampré, foi nomeado para reger a cátedra interinamente. Poucos meses depois, após brilhante concurso de títulos e provas, conquistou o cargo de catedrático. 
Sua atividade didática sempre estêve ligada à Cadeira de Clínica Neurológica. Grande didata, desde 1926 participou ativamente no ensino. A partir de 1938, quando assumiu a cátedra, até 1946, ministrou quase tôdas as aulas teóricas, atividade que, depois, distribuiu entre os docentes e assistentes, nunca delegando, porém, a supervisão geral do curso de graduação. De temperamento reservado e avêsso à conquista fácil de simpatias, sempre relutou em fazer comunicações fora do âmbito da Faculdade de Medicina de São Paulo e nunca se sentiu bem nas agitadas reunióes de congressos médicos.

Entretanto, nunca se recusou a cooperar em iniciativas visando ao progresso da Medicina e, em particular, da Neurologia. Prestou serviços durante as revoluções de 1924 e 1932, respectivamente, como interno em Hospital de Emergência e como neurologista à disposição do Comando da II Região Militar. Prestigiou a Sociedade de Medicina e Cirurgia de São Paulo, na qual ingressou em 1931, apresentando numerosos trabalhos; em 1960 foi presidente dessa Sociedade, agora com o nome de Academia de Medicina de São Paulo. Cooperou, em 1930, na fundação da Associação

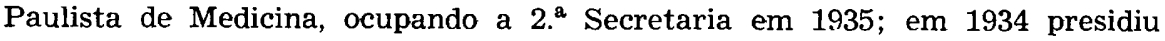
- Departamento de Neuropsiquiatria. Foi eleito, em 1934, sócio honorário da Associação Médica do Instituto Penido Burnier (Campinas). É membro correspondente da Sociedade Brasileira de Neurologia, Psiquiatria e Medicina Legal (Rio de Janeiro). Em 1962 foi eleito presidente da primeira diretoria da Academia Brasileira de Neurologia, filiada à Federação Mundial de Neurologia.

Incentivado pelo espírito entusiasta e comunicativo de seu mestre, Adherbal Tolosa começou a relatar suas observações neurológicas em 1927. Seu interêsse voltou-se para os mais variados setores da Neurologia, como se comprova pelo exame da relação bibliográfica, que se segue a estas notas.

Seus trabalhos sôbre os reflexos cremastéricos deram margem à descrição de variantes na pesquisa e de dissociação nas respostas; estas pesquisas foram condensadas em 1934, na tese de doutoramento de $\mathrm{J}$. da Fonseca Bicudo Jr. que, com tôda a justiça, deu a essa contribuição semiótica a denominação de sinal de Tolosa.

Embora alguns dos reflexos espondílicos já tivessem sido parcialmente estudados por Tschenov, McCarthy, Grossmann e Jarkow'ski, cabe a Adherbal Tolosa o mérito de ter feito estudo de conjunto, sistematizando a pesquisa, uniformizando a semiotécnica e valorizando as respostas. Dentre êsses reflexos Adherbal Tolosa destacou, em 1938, para sua tese de concurso à cátedra de Clínica Neurológica, os reflexos espondilocrurais, demonstrando que sua exaltação em síndromes medulares espásticas é extremamente útil para o diagnóstico topográfico da lesão.

No seu discurso de paraninfo da turma de médicos de 1945, ao invés de acenar para êxitos fáceis e glórias futuras, analisou, com franqueza e objetividade, os percalços do exercício da Medicina. Aconselhou a seus 
discípulos que avaliassem suas vocações, que utilizassem no tratamento apenas recursos realmente úteis, abstendo-se do supérfluo e do não comprovadamente benéfico, que purificassem suas ações na prática do bem e nos ditames da moral. Que fôssem, em suma, justos, honestos, lógicos, bons e dedicados em relação a seus pacientes e a seus colegas.

Como catedrático, sempre procurou incentivar os seus colaboradores da Clínica, destacando-se pela lógica dos argumentos e pelas soluções adotadas após madura reflexão. Embora racionalista, sempre se sentia sob a armadura do frio administrador e da brilhante inteligência, o calor humano de um grande coração. Esses traços de sua personalidade fizeram da Clínica Neurológica uma família unida e solidária, atraindo um número cada vez maior de jovens especialistas.

Em 1966 a Clínica passou a denominar-se Departamento de Neurologia, englobando uma Disciplina autônoma (Neurocirurgia) e duas Disciplinas integrantes (Clínica Neurológica e Clínica Neurológica Infantil). Atualmente, o Departamento conta com um professor associado, 3 professôres de disciplina, 2 professôres-assistentes docentes-livres, 1 professor-assistente doutor, 2 médicos-assistentes docentes-livres, 3 médicos-assistentes doutores, 12 médicos assistentes, 8 plantonistas de neurocirurgia, 7 médicos adidos, 3 residentes de $2 .^{\circ}$ ano, 9 residentes de $10^{\circ}$ ano, 9 estagiários voluntários e 6 estagiários bolsistas.

Desde 1962, quando foi indicado para o cargo pela Congregação da Faculdade de Medicina de São Paulo, ocupa o pôsto de Diretor Clínico do Hospital das Clínicas, cargo em que vem demonstrando senso de responsabilidade, energia, amor à disciplina e ponderação.

Em fins de 1968, após vários anos de um trabalho incansável de revisão crítica dos originais, da primeira à última página, que obrigou os colaboradores de Adherbal Tolosa a refazerem duas, três e mais vêzes o texto até conseguirem o imprimatur do exigente mestre - veio a lume o livro "Propedêutica Neurológica: Temas Essenciais".

Logo depois, por ocasião do $30 .^{\circ}$ ano de cátedra, os seus amigos organizaram uma cerimônia no hall de entrada do Hospital das Clínicas, onde foram expostos vários cartazes retratando o desenvolvimento das atividades do Departamento de Neurologia nos setores de ensino, pesquisa e assistência. Adherbal Tolosa foi saudado pelo Prof. João Alves Meira, Diretor da Faculdade de Medicina da USP, pelo Prof. Antônio B. Lefèvre, em nome dos integrantes do Departamento de Neurologia, e pelo Prof. Cantídio de Moura Campos, seu antecessor na chefia do Corpo Clínico do Hospital das Clínicas. Alguns meses depois, coroando sua carreira, Adherbal Tolosa teve a grande alegria de ver concretizada, com a criação do Instituto de Neurologia e Neurocirurgia, uma das maiores aspirações de seu Departamento.

Para encerrar, cremos justo afirmar que Adherbal Tolosa, cumprindo a promessa feita em seu discurso de posse, soube suceder a Enjolras Vampré. 
1. TOLOSA, A. - Contribuição ao estudo dos pneumococos. Tese de doutoramento. Faculdade de Medicina, São Paulo, 1924.

2. TOLOSA, A. - Perturbações oculares em algumas moléstias nervosas. Bol. Soc. Med. Cirurg. São Paulo, número especial (Semana Oftalmoneurológica), pp. 90-132, 1927.

3. TOLOSA, A. - Sôbre um caso de epilepsia bravais jacksoniana com síndrome humoral de paralisia geral progressiva. Bol. Soc. Med. Cirurg. São Paulo 11:74-78, 1928.

4. VAMPRÉ, E. \& TOLOSA, A. - Sindromes de Villaret (sindrome retroparotidea posterior) e de Jaccod (sindrome petrosfenoidal). Bol. Soc. Med. Cirurg. São Paulo 11:80-85, 1928.

5. VAMPRÉ, E. \& TOLOSA, A. - Sindromes neuro-psico-anêmicas. São Paulo méd. 1:327-359, 1929.

6. GOMES, J. M.; SIlveira, G. F.; ANTUNES, P. C. A. \& TOlosA, A. Desvio do complemento no líquido cefalorraquidiano de leprosos. Brasil-méd. $43: 50,1929$.

7. VAMPRÉ, E. \& TOLOSA, A. - Tumor do quarto ventrículo, ao nivel do bulbo, determinando dissociação da sensibilidade de tipo cortical: diagnóstico diferencial com os tumores parietais. Bol. Soc. Med. Cirurg. São Paulo 14:67-71, 1930 .

8. TOLOSA, A. - Neurites leprosas. Bol. Soc. Med. Cirurg. São Paulo, número especial (Semana das Conferências), pp. 161-181, 1930.

9. TOlosA, A. - Da inexistência de uma síndrome humoral característica da paralisia geral progressiva. Bol. Soc. Med. Cirurg. São Paulo 15:119-132, 1931.

10. VAMPRE, E. \& TOLOSA, A. - Tratamento das sindromes pós-encefalíticas por injeçōes raquídias de Electrargol. Bol. Soc. Med. Cirurg. São Paulo $16: 74,1932$.

11. TOlosA, A. - Retração aponeurótica palmar de Dupuytren, de provável origem medular: coexistência de perturbações sensitivas do tipo siringomiélico. Bol. Soc. Med. Cirurg. São Paulo 16:158-163, 1933.

12. TOlosA, A. \& BICUdo Jr., J. F. - Dissociaçōes do reflexo cremastérico em semiologia neurológica. Bol. Soc. Med. Cirurg. São Paulo 16:177, 1933.

13. VAMPRE, E.; TOLOSA, A.; LONGO, P. W.; LANGE, O.; MINDLIN, H. \& VALLE, J. R. - Tumores múltiplos do eixo cerebrospinal. Bol. Soc. Med. Cirurg. São Paulo 16:177, 1933.

14. TOLOSA, A. \& LANGE, O. - Tumor da fossa craniana posterior: aracnoidite cística da cisterna magna, diagnosticada pelas provas de Stookey-Queckenstedt. Rev. otolaring. São Paulo 2:27-33, 1934.

15. TOlOSA, A. - Sôbre um caso de siringomielia: efeitos benéficos da roentgenterapia profunda; dissociação cremastérica do segundo tipo. Rev. Ass. paul. Med. 4:290-291, 1934. 
16. TOLOSA, A. - Dissociação do reflexo cremastérico: estudo físioclínico sôbre a via centrípeta. Rev. Neurol. Psiquiat. São Paulo 1:31-40, 1934.

17. TOLOSA, A. - As neurodocites luéticas do II par craniano na oftalmoplegia sensitivo-sensório-motora. Rev. Neurol. Psiquiat. São Paulo 1:142-156, 1935.

18. TOLOSA, A. \& REZENDE, M. O. - Sindrome dissociada alterna do virI par craniano: lues labiríntica destrutiva. Rev. otolaring. São Paulo 3:112-122, 1935.

19. VAMPRÉ, E. \& TOLOSA, A. - Sinal do balanço do pé (Sicard) sem lesões piramidais: estudo anátomo-clínico a propósito de um caso de poliomielite anterior crônica. Rev. Ass. paul. Med. 7:57-66, 1935.

20. TOlOSA, A.; GAMA, C. \& BASTOS, F. O. - Tumor da fossa craniana posterior: diagnóstico de localização no IV ventrículo pela ventriculografia; confirmação anátomo-patológica. An. Fac. Med. São Paulo 11:133-142, 1936.

21. TOlOSA, A. \& ARAUJO, O. P. - Nova contribuição para o estudo das lesões sifiliticas da órbita: heredolues com lesão dos ossos da face, atingindo o assoalho orbitário. Arq. Inst. Penido Burnier 4:175-182, 1936.

22. TOlOSA, A. \& GAMA, C. - Compressão da medula dorsal média por meningeoma psamomatoso. Extirpação cirúrgica: cura. Rev. Ass. paul. Med. 12:17-28, 1938 .

23. TOLOSA, A. - Considerações sôbre a indicação cirúrgica nos traumatismos medulares fechados. Rev. Ass. paul. Med. 12:93-106, 1938.

24. FONSECA, A. \& TOLOSA, A. - Exoftalmo na disostose hipofisária ou doença de Schüller-Christian. Rev. Oftal. São Paulo 6:10-20, 1938.

25. TOlosA, A. - O sinal de Babinski da mão. Rev. Ass. paul. Med. 13:29-34, 1938.

26. TOlOSA, A. - Desdobramento da sindrome piramidal. An. paul. Med. Cirurg. 36:231-237, 1938 .

27. TOlosA, A. - Conceito e posição da comoção medular em patologia. An. Fac. Med. Montevideo 23:3-23, 1938.

28. VAMPRE, E. \& TOLOSA, A. - Cataplexia de causa mecânica: perda súbita do tono de atitude por percussão do crânio. São Paulo méd. 11:31-38, 1938.

29. TOLOSA, A. - O liquido cefalorraquidiano em semiologia neurológica. Rev. clín. São Paulo 4:51-67, 1938.

30. TOLOSA, A. - Estudo clínico dos reflexos espondileus, particularmente do reflexo espondilocrural. Tese para concurso à Cátedra de Clínica Neurológica, Faculdade de Medicina, São Paulo, 1938.

31. TOLOSA, A. \& VENTURI, V. -- A propósito de uma síndrome de Weber de origem luética. Rev. Neurol. Psiquiat. São Paulo 5:1-12, 1939.

32. TOLOSA, A. \& SAVOY, C. V, - Sôbre um caso de polineurite sulfamídica. São Paulo méd. 12:269-279, 1939.

33. TOLOSA, A. - Contribuição otolaringoftalmológica para o diagnóstico das moléstias nervosas. Rev. Biol. Med. (São Paulo) 1:1-14, 1940. 
34. TOlOSA, A.; JUlião, O. F. \& RIBAS, J. C. - Tabes e hemiplegia: considerações em tôrno de dois casos. Rev. Ass. paul. Med. 17:165-180, 1940.

35. TOlosA, A. - Considerações clínicas e fisiopatológicas sôbre a sindrome de Brown-Séquard. Arq. Cirurg. clín. exp. 5:593-606, 1941.

36. TOlosa, A. \& SAVOY, C. V. - Estudo clínico e fisiopatológico de dois casos de miastenia grave, com referência particular à ação da prostigmina. Arq. Cirurg. clín. exp. 5:607-630, 1941.

37. TOLOSA, A. \& VENTURI, V. - Consideracões sôbre um caso de hemi-hipertonia palidal. Arq. Cirurg. clín. exp. 5:631-644, 1941.

38. TOlOSA, A. \& RIBAS, J. C. - Picnolepsia. Arq. Cirurg. clín. exp. 5:645656, 1941.

39. TOLOSA, A. \& GAMA, C. - Cordotomia anterolateral numa sindrome dolorosa irredutivel do membro inferior. Arq. Cirurg. clín. exp. 5:689-702, 1941.

40. TOLOSA, A. - Conceito atual do sistema extrapiramidal. Rev. Neurol. Psiquiat. São Paulo 8:229-242, 1942.

41. TOlosA, A. \& CAETANo DA SIlva Jr., J. A. - Consideracooos semióticas sôbre o automatismo medular. Arq. Cirurg. clin. exp. 6:1088-1098, 1942.

42. TOlOSA, A.; MINDliN, H. S. \& MAFFEI, W. E. - Sindrome de BrownSéquard de natureza sifilitica: estudo anátomo-clínico. Med. Cirurg. Farm. n.o 83, pp. 1-11, 1943 .

43. TOLOSA, A. \& GAMA, C. - Tumores paradoxais do encéfalo: a propósito de cinco casos de glioblastoma multiforme operados. Arq. Neuro-psiquiat. (São Paulo) 1:9-25, 1943.

44. TOlOSA, A. - Distúrbios vasculares do cérebro e seu tratamento. Arq. Neuro-psiquiat. (São Paulo) 2:73-82, 1944.

45. TOLOSA, A. - Clínica Neurológica da Faculdade de Medicina da Universidade de São Paulo: breve notícia de suas atividades durante o periodo 19381943. Arq. Neuro-psiquiat. (São Paulo) 2:203-210, 1944.

46. TOLOSA, A. - Oração de paraninfo da turma de 1945. Rev. Med. (São Paulo) 30:133-143, 1946.

47. 'TOlOSA, A.; CAETANO DA SIlva Jr., J. A. \& TENUTO, R. A. - Tuberculoma cerebral: extirpação cirúrgica. Arq. Neuro-psiquiat. (São Paulo) 4:2833, 1946.

48. TOlOSA, A. \& CAETANO DA SIlvA Jr., J. A. - Penicilinoterapia em um caso de meningorradiculite luética. Arq. Neuro-psiquiat. (São Paulo) 4:58-60, 1946.

49. TOLOSA, A.; TENUTO, R. A. \& ASSIS, J. L. - Desordens da sensibilidade nas tratotomias piramidais cervicais. Arq. Neuro-psiquiat. (São Paulo) 5:235$243,1947$.

50. TOlosa, A. \& CANElAS, H. M. - Síndromes do núcleo rubro: a propósito de três casos com etiologia sifilítica, um dos quais associado a mioclonias velofaringolaringeas. Arq. Neuro-psiquiat. (São Paulo) 8:211-226, 1950. 
51. TOlOSA, A.; Lefívre, A. B. \& AIDAR, O. - Particularidades da apraxia frontocalosa. Arq. Neuro-psiquiat. (São Paulo) 8:235-242, 1950.

52. TOLOSA, A.; CANELAS, H. M.; TENUTO, R. A. \& RICCIARDI-CRUZ, O. Compressões medulares provocadas por mielomas vertebrais. Arq. Neuropsiquiat. (São Paulo) 14:101-116, 1956.

53. TOLOSA, A.; SPINA-FRANCA, A. \& LACAZ, C. S. - Criptococose do sistema nervoso central: registro de um caso. Arq. Neuro-psiquiat. (São Paulo) 14:171-178, 1956 .

54. TOLOSA, A. - O problema clínico das epilepsias. Rev. paul. Med. 60:271$273,1962$.

55. CANELAS, H. M.; MARQUES-ASSIS, L.; De JORGE, F. B.; TOLOSA, A. \& CINTRA, A. B. U. - Disorders of copper metabolism in epilepsy. Acta neurol. scand. 40:97-106, 1964 .

56. TOLOSA, A. \& CANELAS, H. M. - Considerações sôbre os resultados da aplicação de um teste para avaliação do aproveitamento no curso de Neurologia. Rev. Med. (São Paulo) 49:63-66, 1965.

57. Tolosa, A. - A residência no ensino médico e a pesquisa. Rev. Hosp. Clín. Fac. Med. São Paulo 21:155-158, 1966.

58. TOlosa, A. \& CANElas, H. M. - Motricidade. In Tolosa, A. \& Canelas, H. M.: Propedêutica Neurológica, Temas Essenciais. Procienx, São Paulo, 1969, pp. 3-50.

59. TOLOSA, A. \& CANELAS, H. M. - Sensibilidade. In Tolosa, A. \& Canelas, H. M.: Propedêutica Neurológica, Temas Essenciais. Procienx, São Paulo, 1969, pp. 51-68. 